\title{
Study on the Amount of N-Methyl-2-Pyrrolidone Decreasing by Butanol as a Solvent in Re-refining of Used Lubricating Oils
}

\author{
Mohamed H. Majed ${ }^{1}$, Amer A. Amer², and Mohamed A. Mohamed ${ }^{1 *}$ \\ ${ }^{I}$ Department of Chemical Eng., Alexandria Faculty of Eng., Alexandria University, Alexandria, \\ Egypt. \\ ${ }^{2}$ Former general manager at Alexandria Petroleum Company, Alexandria, Egypt \\ *(Corresponding author: mohamedattiamohamed2008@gmail.com)
}

\begin{abstract}
This study purpose is to check a new technique in solvent extraction process on used lubricating oils using design of experiments (DOE) generated by MINITAB. In addition, study technique for decreasing the amount of N-Methyl-2-Pyrroidone used in the re-refining of used oil thus decreasing the operating cost of the extraction process. The experiments were done on pre-treated used lubricating oils, which was obtained from Alexandria Petroleum Company facility where light hydrocarbons and water were eliminated from it. Solvent extraction technique was done on the used lubricating oils using N-Methyl-2-Pyrrolidone (NMP) and butanol as a solvents. Different factors were studied by bench scale experiments such as: Solvent to solvent weight ratios, Solvent to oil weight ratios, mixing time, mixing speed and the extraction temperatures. A statistical analysis computer software (MINITAB version 17) was used to investigate those factors which affect the percent sludge removal from the used lubricating oils. Furthermore, the data obtained from both bench scale experiments and statistical analysis computer software shows that the most significant factors affecting the percent sludge removal from used lubricating oils was solvent-to-solvent weight ratios, while the least significant factor was the extraction temperature.
\end{abstract}

Keywords: Used oils; NMP; MINI-TAB; Solvent Extraction; Recycling.

\section{Introduction}

Lubricating oils are one of the very important liquids that are used in nearly all machines and vehicles. The importance of lubricating oil is the dual action which deal with heat transfer and friction reduction generated in the combustion engines [1,2] .The lubricating oil become incompetent for further use for the given reasons: contaminants accumulations in the oil and the chemical changes in the lubricating oil. Due to resource preservation and issues related to oil disposal the demand of waste oil re-refining become an important option [3]. Process for recycling the waste or used lubricating oils differs from simple settling or filtration to solvent extraction process, vacuum distillation or a mix of these processes and other processes [4,5]. Solvent extraction processes have received large attention among many processes practiced for recycling used lubricating oils during recent years [6].

The classic and common acid-clay treatment have been replaced by the solvent extraction technique. In this process, the solvent or solvents have to mix with the used lubricating oil in a convenient ratio and fully miscible with the base oil and separate impurities which flocculates and settle down by gravity action, then the used solvent is recovered for recycling purpose by distillation $[7,8]$.

Essentially, there are two types of solvent extraction methods. One is done using a single or composite solvents [9]. Using Solvent extraction can overcome problems resulting from using the classic methods like reducing the production of hazardous byproducts (acid sludge), the need of high temperature and pressure operation or the need of periodic replacement of catalyst used in the process that is highly cost asset [10,11].

The N-Methyl-2-Pyrrolidone (NMP) has advantages over other solvents such as non-toxic nature, high solvent power, high selectivity for aromatic hydrocarbons and the ease of recovery from solutes $[12,13]$. The alcoholic solvents such as butanol have a hydroxyl group (OH-), which give an electrostatic media that allow fine particles to agglomerate into large flakes. The higher solubility in the base oil 
gives indication to higher miscibility of the solvent in base oil that decreases the amount of oil losses in the sludge [14,15]. Fractional factorial design are experimental designs consisting of accurate subsets of experimental runs of a full factorial design. Moreover, it explores the effect of different combinations of factor values on process outputs that are carried out on a subset of all possible values rather than the complete set of possible values. Fractional factorial designs are used when only some possible values of factors in a process are seen as pertinent or relevant to the business or manufacturing process being modeled, furthermore, the fractional factorial design are suitable choice when resources are limited or the number of factors in the design are large [16].

\section{Materials}

\subsection{Used lubricating oil}

The samples in this study was collected form the output of unit 10 in used oil re-refining department on Alexandria Petroleum Company (A.P.C) located at Egypt which uses a KTI re-refining technology. The input of unit 10 is used lubricating oil that was gathered from different service stations where it is allowed to settle in tanks so that the free water and suspended solids could be removed.

In unit 10 (unit located at Alexandria Petroleum Company), many impurities, water and gas oil were separated from used oil. The feed pass through a series of filters to remove and strip solids and impurities then the used oil neutralized by the addition of 10 percent sodium hydroxide in a neutralization vessel. Water was separated in a water removal vessel at temperature of $160{ }^{\circ} \mathrm{C}$ and the temperature of the used oil is raised up to $260{ }^{\circ} \mathrm{C}$ under vacuum pressure in a distillation column to remove gasoil and light hydrocarbons. Where this lead to the presence of lubricating oil which has been used in this study and can be considered as a pretreated oil after the removal of impurities, gas oil and water [17].

\subsection{Solvents used in the study}

Two solvents have been used in this study, which are N-Methyl-2-Pyrrolidone and Butanol as shown in Table (1).

Table 1- Solvents used

\begin{tabular}{|c|c|c|}
\hline Physical property & Butanol & NMP \\
\hline Chemical formula & $\mathrm{C}_{4} \mathrm{H}_{10} \mathrm{O}$ & $\mathrm{C}_{5} \mathrm{H}_{9} \mathrm{ON}$ \\
\hline Density $\left(\mathrm{gm} / \mathrm{cm}^{3}\right)$ & 0.81 & 1.028 \\
\hline Boiling point $\left({ }^{\circ} \mathrm{C}\right)$ & 117 & 202 \\
\hline
\end{tabular}

\subsection{Experimental Procedures}

1. Prepare 0.25 and 0.75 solvent NMP/solvent butanol (\%wt.) in a two small vessels.

2. Mix $(20,60) \mathrm{gm}$. Of prepared solvent with $10 \mathrm{gm}$. of used lubricating oil to prepare a solvent to oil ratio (2-6) wt. \% respectively.

3. Expose the mixture to the conditions mentioned in Table (2), according to run order.

4. Put the mixture to a separating funnel to separate for one hour.

5. There will be two phases extract phase (base oil + solvent) and raffinate phase (sludge).

6. The sludge is placed in a previously known beaker and was oven dried at $205{ }^{\circ} \mathrm{C}$ for $30 \mathrm{~min}$ where a constant weight of sample is maintained then let cooled to room temperature to obtain the weight of sludge where the percent sludge removal is calculated (PSR).

\section{Results and Discussions}

The effect of percent sludge removal (PSR) using NMethyl-2-Pyrrolidone as a solvent has been studied according to the following variables (solvent to oil weight ratio, Extraction temperature, mixing speed, mixing time and the addition of potassium hydroxide).

\subsection{Effect of solvent to oil weight ratio on PSR}

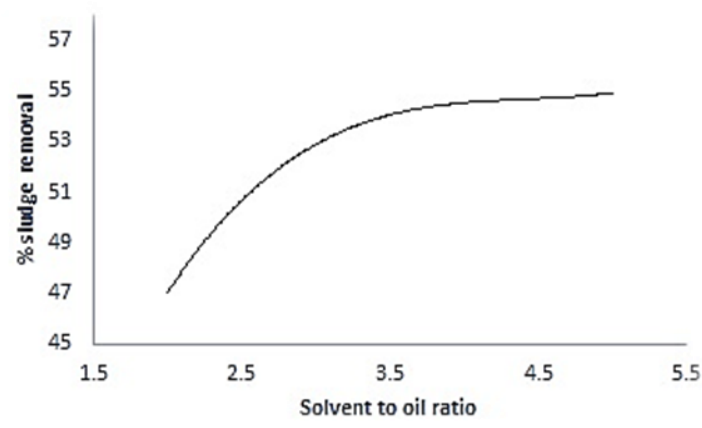

Figure 1- Effect of solvent to oil ratio

Figure (1) shows that as the solvent to oil ratio increases the percent sludge removal increases and this is related to as the amount of solvent increases the solvent power increases and the medium mutual solubility of the oil in the solvent increase. The figure also shows that the percent sludge removal increases as solvent to oil weight ratio increases until a value of solvent to oil ratio of three. 


\subsection{Effect of extraction temperature on PSR}

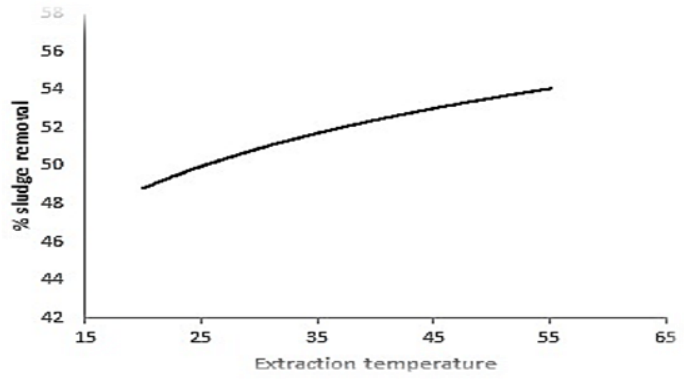

Figure 2- Effect of extraction temperature

Figure (2) shows that there is an increase in the percent sludge removal as the extraction temperature increases up to extraction temperature $50^{\circ} \mathrm{C}$. The effect of the extraction temperature may be related to the increase of the dissolving action of the solvent with increasing the temperature. Furthermore, increasing the temperature lead to increasing the solvent power of the solvent and increase the solubility of undesirable materials especially polycondensed aromatics in the solvent.

\subsection{Effect of mixing speed on PSR}

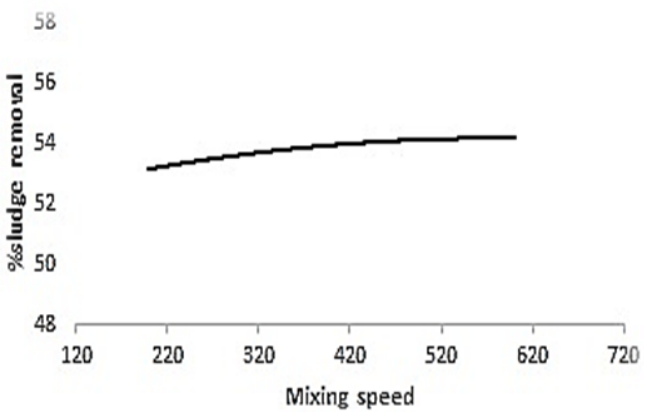

Figure 3- Effect of mixing speed

Figure (3) show there is a slightly increase in percent sludge removal as the mixing speed increases. Increasing the mixing speed increase the distribution of solute molecules with the solution, which create more effective contact areas for mass transfer between oil and solvent. Where the mixing speed stabilize the percent sludge removal at $400 \mathrm{rpm}$.

\subsection{Effect of mixing time on PSR}

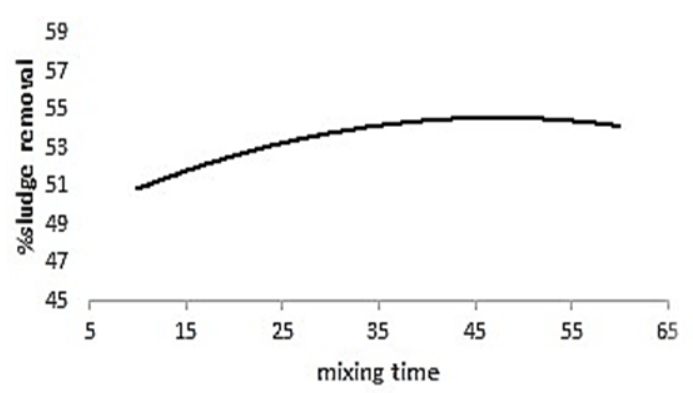

Figure 4- Effect of mixing time

Figure (4) shows there is an increase in percent sludge removal as the mixing time increase where the value of percent sludge removal stabilize at $30 \mathrm{~min}$., the action of increasing the mixing time is related to increasing the time of interaction between the molecules of the oil with the molecules of the solvent.

\subsection{Effect of Potassium Hydroxide addition on PSR}

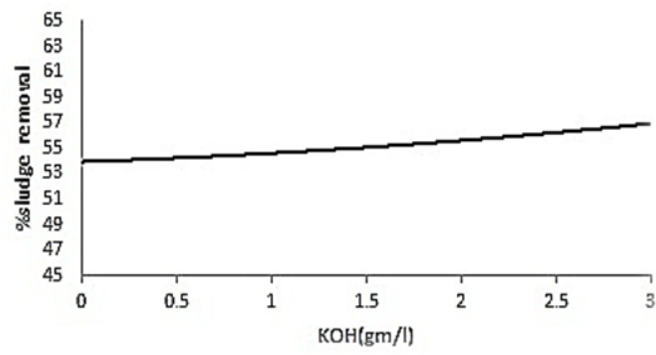

Figure 5- Effect of $\mathrm{KOH}$ concentration

Figure (5) shows that, as the amount of $\mathrm{KOH}$ increase there is a slight increase in the percent sludge removal where the percent sludge removal value stabilize at potassium hydroxide concentration of $2 \mathrm{gm}$. /L. this is related to the effect of potassium hydroxide to neutralize the acid compounds and subsequent precipitation where the $(\mathrm{OH}-)$ group break the hydrogen bond between the polar impurities. 


\subsection{Effect of using a mixture of NMP and Butanol on PSR}

Statistical analysis of the model was performed to evaluate the analysis of variance (ANOVA). Based on the preliminary experimental results, the levels chosen for the independent variables; solvent to solvent weight ratio (x1), solvent to oil weight ratio (x2), Temperature of extraction (x3), mixing time (x4) and mixing speed (x5) were shown in Table (2). ( $\mathrm{R}=$ real value $\& \mathrm{C}=$ coded value $)$

Table 2- Coded parameters

\begin{tabular}{|l|l|l|l|l|l|l|l|l|l|}
\hline \multicolumn{2}{|c|}{$\begin{array}{c}\text { Ext. } \\
\text { Temp }\end{array}$} & \multicolumn{2}{c|}{$\begin{array}{c}\text { Mix } \\
\text { time }\end{array}$} & \multicolumn{2}{c|}{$\begin{array}{c}\text { Mix } \\
\text { speed }\end{array}$} & \multicolumn{2}{c|}{$\begin{array}{c}\text { s/s } \\
\text { (\%wt.) }\end{array}$} & \multicolumn{2}{c|}{$\begin{array}{c}\text { s/o } \\
\text { (\%wt.) }\end{array}$} \\
\hline $\mathrm{R}$ & $\mathrm{C}$ & $\mathrm{R}$ & $\mathrm{C}$ & $\mathrm{R}$ & $\mathrm{C}$ & $\mathrm{R}$ & $\mathrm{C}$ & $\mathrm{R}$ & $\mathrm{C}$ \\
\hline $\mathrm{X} 3$ & $\mathrm{x}_{3}$ & $\mathrm{X} 4$ & $\mathrm{x}_{4}$ & $\mathrm{X} 5$ & $\mathrm{x}_{5}$ & $\mathrm{X} 1$ & $\mathrm{x}_{1}$ & $\mathrm{X} 2$ & $\mathrm{x}_{2}$ \\
\hline 25 & -1 & 10 & -1 & 200 & -1 & 0.25 & -1 & 2 & -1 \\
\hline 60 & 1 & 50 & 1 & 600 & 1 & 0.75 & 1 & 6 & 1 \\
\hline
\end{tabular}

The values of the independent variables were coded as the variables in the range of +1 and -1 level. Thus, 24 run was needed in total (According to DOE). The mean value of the response (Percent sludge removal) was obtained at different conditions mentioned and summarized in Table (3).

Table 3- PSR predicted and experimental results

\begin{tabular}{|c|c|c|c|c|c|c|c|}
\hline \multirow{2}{*}{$\mathrm{N}$} & \multirow{2}{*}{$\mathrm{x}_{1}$} & \multirow{2}{*}{$\mathrm{x}_{2}$} & \multirow{2}{*}{$\mathrm{x}_{3}$} & \multirow{2}{*}{$\mathrm{x}_{4}$} & $\mathrm{x}_{5}$ & \multicolumn{2}{|c|}{ PSR } \\
\hline 1 & -1 & -1 & -1 & -1 & 1 & 22.19 & 22.0163 \\
\hline 2 & -1 & -1 & 1 & -1 & -1 & 35.74 & 36.1830 \\
\hline 3 & 1 & 1 & -1 & -1 & -1 & 45.73 & 45.2496 \\
\hline 4 & -1 & -1 & -1 & 1 & 1 & 19.51 & 23.1963 \\
\hline 5 & -1 & -1 & 1 & -1 & -1 & 33.82 & 36.1830 \\
\hline 6 & -1 & -1 & 1 & 1 & -1 & 34.26 & 36.5963 \\
\hline 7 & 1 & 1 & -1 & 1 & -1 & 46.82 & 48.3430 \\
\hline 8 & 1 & 1 & 1 & -1 & 1 & 51.08 & 53.0896 \\
\hline 9 & 1 & 1 & 1 & -1 & 1 & 50.24 & 53.0896 \\
\hline 10 & -1 & -1 & -1 & 1 & 1 & 22.97 & 23.1963 \\
\hline 11 & 1 & 1 & -1 & -1 & -1 & 42.63 & 45.2496 \\
\hline 12 & 1 & 1 & -1 & -1 & -1 & 43.77 & 45.2496 \\
\hline 13 & 1 & 1 & -1 & 1 & -1 & 46.21 & 48.3430 \\
\hline 14 & -1 & -1 & -1 & -1 & 1 & 18.86 & 22.0163 \\
\hline 15 & -1 & -1 & 1 & 1 & -1 & 36.65 & 36.5963 \\
\hline 16 & 1 & 1 & 1 & 1 & 1 & 53.02 & 55.8863 \\
\hline 17 & -1 & -1 & 1 & -1 & -1 & 32.17 & 36.1830 \\
\hline 18 & 1 & -1 & -1 & -1 & 1 & 22.19 & 22.0163 \\
\hline 19 & 1 & 1 & -1 & 1 & -1 & 46.26 & 48.3430 \\
\hline 20 & -1 & -1 & -1 & 1 & 1 & 20.39 & 23.1963 \\
\hline 21 & -1 & -1 & -1 & -1 & 1 & 21.53 & 22.0163 \\
\hline 22 & 1 & 1 & 1 & -1 & 1 & 50.50 & 53.0896 \\
\hline 23 & -1 & -1 & 1 & 1 & -1 & 37.18 & 36.5963 \\
\hline 24 & 1 & 1 & 1 & 1 & 1 & 55.37 & 55.8863 \\
\hline
\end{tabular}

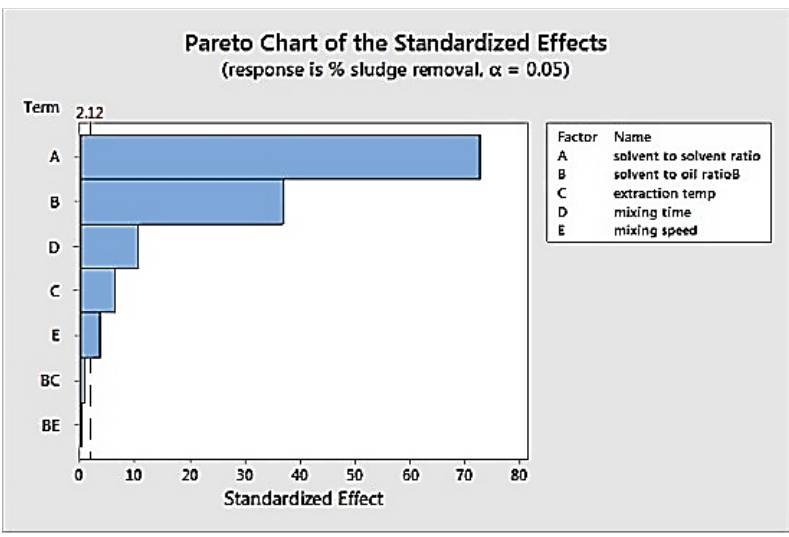

Figure 6- Pareto chart of standardized effects

Figure (6), Shows the factors that have effect on the present sludge removal arranged from the highest (solvent-to-solvent ratio) significant effect to the least significant effect (mixing speed). Furth more, the interactions between the solvent to oil ratio and both extraction temperature and the mixing speed show non-significant effect on the percent sludge removal.

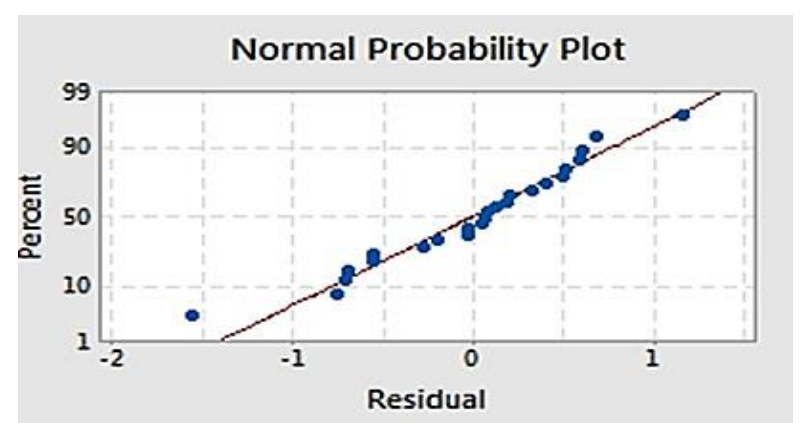

Figure 7- normal probability plot

Figure (7) give us indication about the adequacy of the least square fit according to the regression model, showing a straight line and normal distribution of the residual which emphasis the model of the study.

Table (4) illustrates the factors which have the attitude to significantly make change in the percent sludge removal. The factors are specified with both (T-value) and (P-value), where larger the magnitude of T-value and the smaller the P-value shows the considerable significance of the corresponding coefficient. According to the confidence level $(\mathrm{P}<0.05)$, the solvent-to-solvent ratio has the highest significant effect while the mixing speed has the least significant effect on the percent sludge removal. Furth more, the interactions between the solvent to oil ratio, mixing speed and extraction temperature show non-significant effect. 
Table 4- Parameters coefficients and T-values

\begin{tabular}{|c|l|l|l|l|}
\hline Term & Coef & SE- coef & T-value & P-value \\
\hline Constant & 38.297 & 0.301 & 127.34 & 0.000 \\
\hline $\mathrm{x}_{1}$ & 10.358 & 0.301 & 34.44 & 0.000 \\
\hline $\mathrm{x}_{2}$ & 5.225 & 0.301 & 17.37 & 0.000 \\
\hline $\mathrm{x}_{3}$ & 0.942 & 0.301 & 3.13 & 0.006 \\
\hline $\mathrm{x}_{4}$ & -1.806 & 0.301 & -6.00 & 0.000 \\
\hline $\mathrm{x}_{5}$ & 0.388 & 0.301 & 1.29 & 0.007 \\
\hline$x_{2} * x_{3}$ & 0.322 & 0.301 & 1.07 & 0.301 \\
\hline$x_{5} * x_{2}$ & -0.184 & 0.301 & -0.61 & 0.549 \\
\hline
\end{tabular}

From the regression analysis a coded equation can be driven as shown in Eq. (1) as following:

Regression equation in coded unit as shown in Table2:

$\%$ sludge removal $=$

$7.60+41.43 \times 1+2.406 \times 2+0.0171 \times 3-0.0903 \times 4+$ $0.00378 \times 5+0.00919(\mathrm{x} 2 * \mathrm{x} 3)-0.000460(\mathrm{x} 2 * \mathrm{x} 5)$

However, after analysis of variance (ANOVA) of the obtained data, analysis of regression model and excluded the non-significant effect from the Eq. (1) the following Eq. (2) could be driven as:

Percent sludge removal $=$

$$
6.77+41.43 \mathrm{X} 1+2.612 \mathrm{X} 2+0.0539 \mathrm{X} 3-0.0903 \mathrm{X} 4
$$

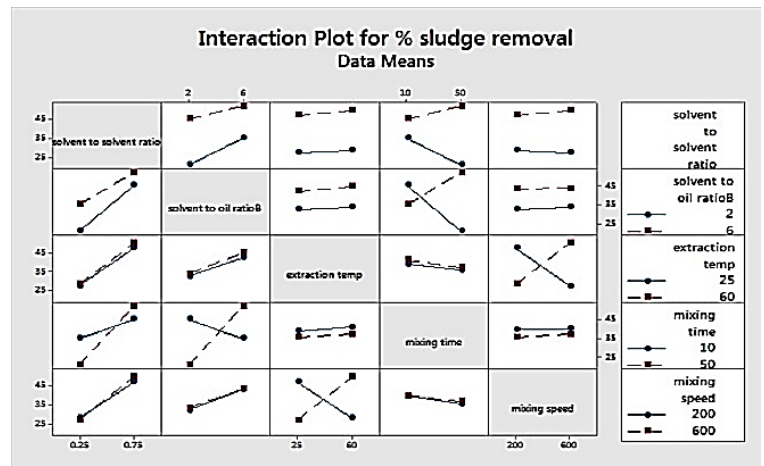

Figure 8- Interactions plot

This interaction plot is shown in Figure (8) shows an indication and analysis of the behavior of each factor with respect to the percent sludge removal which assurance the previous plots with respect to the percent sludge removal. For the factor solvent-tosolvent ratio, the graph shows that the relation between solvent-to-solvent ratio and solvent to oil ratio shows the highest percent of sludge removal for the solvent to oil ratio six more than that of two at the same solvent-to-solvent ratio. In addition, the graph of solvent-to-solvent ratio and extraction temperature show that the highest percent sludge removal exists when the extraction temperature is $60{ }^{\circ} \mathrm{C}$ larger than that of $25^{\circ} \mathrm{C}$ at the same solvent-to-solvent ratio.

\section{Cost reduction}

According to Richest Group (China Chemical supplier Company) which is located at Shanghai, China. The cost of N-Methyl-2-Pyrrolidone is about 809.26 EGP/Kg. whereas, According to ElGomhouria Company for trading chemicals \& medical appliances which is located at Alexandria, Egypt. The cost of butanol is about 80 EGP/liter. Shown in table (5).

Table 5- Cost reduction

\begin{tabular}{|c|c|}
\hline Description & Cost (EGP) \\
\hline $\begin{array}{c}\text { Liq. Extraction for 10 gm. Of used oil } \\
\text { by NMP }\end{array}$ & 40.463 \\
\hline $\begin{array}{c}\text { Liq. Extraction for 10 gm. of used oil } \\
\text { by Mixture of NMP and butanol }\end{array}$ & 37.89 \\
\hline $\begin{array}{c}\text { Saving for using mix. Solvent of NMP } \\
\text { and butanol for 1 kg of used oils }\end{array}$ & 256.482 \\
\hline
\end{tabular}

Table (6) shows the improvements in the physical properties of the used lubricating oils after being rerefined using liquid extraction technique using a mixture of N-Methtyl-2-Pyrrolidone and butanol.

Table 6- Oil physical analysis

\begin{tabular}{|l|l|l|l|}
\hline Test & Method & Before & After \\
\hline Flash Point ${ }^{\circ} \mathrm{C}$ & ASTM-D92 & 112 & 180 \\
\hline $\begin{array}{l}\text { Kinematic } \\
\text { viscosity @40 }\end{array}$ & ASTM-D445 & 133.67 & 90.75 \\
\hline $\begin{array}{l}\text { Kinematic } \\
\text { viscosity @ 100 }\end{array}$ & ASTM-D445 & 14.32 & 10.50 \\
\hline Viscosity index & ASTM-D2270 & 106 & 108 \\
\hline Color & $\begin{array}{l}\text { ASTM color- } \\
\text { D1500 }\end{array}$ & ----- & +3 \\
\hline Pour point & ASTM-D97 & -3 & -3 \\
\hline
\end{tabular}

\section{Conclusions}

Solvent extraction using a mixture of N-Methyl-2Pyrrolidone and Butanol for used lubricating oil recycling has been found to be a good and effective method for the reduction of the amount of N-Methyl2-Pyrrolidone used as a solvent in used lubricating oil recycling. Furthermore, from the data collected and analysis of variance (ANOVA) it shows that the highest significant factor for percent sludge removal was the solvent-to-solvent weight ratio while the least one was the extraction temperature. In addition, the experimental results show that both the interactions of solvent to oil weight ratio, extraction temperature 
and mixing speed have found to be non-significant effect where there effects on the percent sludge removal could be neglected.

\section{References}

[1]. I.G. Rafie, R. Mohammed, Waste lubricating oil treatment by extraction and adsorption. Chemical Engineering Journal.2013, vol. (220), 343-351.

[2] P. Surinder, Petroleum Fuels Manufacturing Handbook. MC-Graw Hill, New York, United states, 2010.

[3] A.S. Gabrah, Solvent extraction parameters in re-refining of used lube oils by box-behnken Experimental design. American Journal of Environmental Engineering and Science.2015, 2, 6, 108-113.

[4] M.H. Ahmed, Samir Gabrah, Used lubricating oil re-refining by solvent extraction. LAP LAMBERT Academic publishing, Germany. 2015.

[5] I. Doaa, Recycling of used engine oil by different solvents. Egyptian Journal of Petroleum, vol. (27), 221-225.

[6] H.A. Elsayed, E. A.-S.-R. , Re-refining of waste lube oil via solvent Extraction followed by catalytic hydrotreatment. Egypt. J. Chem, 2015, 58, 6-10.

[7] C. Shrikannan, Studies on reuse of re-refined used automotive lubricating oil. Research Journal of Engineering Science, vol. (6), 2014, $8-14$

[8] J. Rincon, Regeneration of used lubricating oil by polar solvent extraction. Industrial and Engineering Chemistry Research, vol (44), 2005, 373-379.

[9] H.A.Durrani, M.I. Panhwar \& R.A.Kazi, Determining an efficient solvent extraction parameters for re-refining of waste lubricating oils. Mehran University research journal of engineering and technology, vol. (31), 2012, 265-270.
[10] M. Al-Ghoti, Virgin and recycled engine oil differentiation: A spectroscopic study, Journal of Environmental management, vol. (74), 2009, 187-195.

[11] J. lukic, A. Orlovic, M. Spiteller, J. Jovanovic \& D. Skala, Re-refining of waste mineral insulating oil by Extraction with N-Methyl-2Pyrrolidone. Separation and Purification technology, 2006, 150-156.

[12] Ahmed, S., Used lubricating oils re-refining by solvent extraction. M.Sc. Thesis, faculty of engineering, Alexandria University, Egypt. 2009.

[13] E. Epelle, A comparative study on the solvent powers of phenol, furfural and NMP in improving the viscosity index of spent lubricating oil. International Research Journal on Engineering, vol. (3), 2016, 8-24.

[14] J. Speight, Chemistry and technology of petroleum (Fourth Edition), CRC Press, 2006, USA.

[15] M. Roci, Minimizing Variation in width and height of cutting tool inserts. KTH Publications 2016.

[16] X. Ding, W. Wong, \& H. Quan Xu, Application of fractional designs to study drug Combinations. Statistics in medicine, 2012, 307-318.

[17] Re-refining Spent Oil Department, Alexandria Petroleum Company (APC). https://www.alex-petroleum.com/index.html 